\title{
AN INVESTIGATION OF THE RECENT INCREASE IN THE RATE OF NOTIFICATION OF RESPIRATORY TUBERCULOSIS

\author{
BY
}

C. R. LOWE and J. E. GEDDES

From the Department of Social Medicine, University of Birmingham

In England and Wales during the past decade a paradoxical situation has arisen in that there has been an increase in the number of notifications of respiratory tuberculosis at a time when death rates are falling more rapidly than ever before. The most probable explanation of this phenomenon is the one usually given, namely that the increase in notifications is due to more effective case finding, although the possibility that there has also been an increase in the amount of clinically significant pulmonary tuberculosis cannot be said to have been excluded.

During the 20 years between the two world wars both notification rates and death rates showed a slow but regular improvement. In 1918 more than 30,000 deaths were attributed to respiratory tuberculosis; by 1938 the number had declined by one third to a little over 21,000 . In the same period the annual number of notifications fell from 70,000 to less than 38,000 , a reduction of almost half. At the beginning of the second world war there was an increase in the annual number of both deaths and notifications, but, whereas the number of deaths soon began to fall again-and at an accelerated rate (only 12,031 persons were reported to have died from respiratory tuberculosis in 1951) the increase in notifications was more than maintained $(42,696$ notifications of respiratory tuberculosis were made in 1951, an increase of 5,000 over 1938). The same trend in notification and death rates can be illustrated from recent experience in Scandinavia and America (Stocks, 1952). It is generally believed that the rise in notification and death rates during the early war years reflects an increase in the incidence of tuberculosis brought about by adverse conditions, and that the rapid fall in death rates since the war is to be attributed to advances in therapy.

In the report which follows data collected from records held at the Birmingham Chest Clinic are used in an attempt to discover whether the present high rate of notification is due to a raised incidence of the disease, or to improved case finding.

Secular Trend of Notifications and Deaths

The Figure shows secular variations in the numbers of notifications and deaths from respiratory tuberculosis in Birmingham during the past 30 years.
The data have not been expressed as rates because for the war years the related population cannot be estimated reliably. For the present purpose, however, there is little to choose between numbers and crude rates, particularly since between 1931 and 1951 the population of Birmingham has shown only a relatively small increase (from $1,002,603$ to $1,112,340$ ) in comparison with the magnitude of the change in number of notifications and deaths. From 1920 until about 1935 notifications decreased rapidly; the number of deaths remained fairly constant until 1933, but fell slightly between 1933 and 1938 . During recent years notifications have risen (from 899 in 1940 to 1,242 in 1952). Deaths, on the other hand, after a small increase at the beginning of the war, have continued to fall; indeed, over the past 6 years, the rate of decrease has rapidly accelerated, and the number of deaths reported in 1952 (280) was considerably less than half the number in 1947 (691).

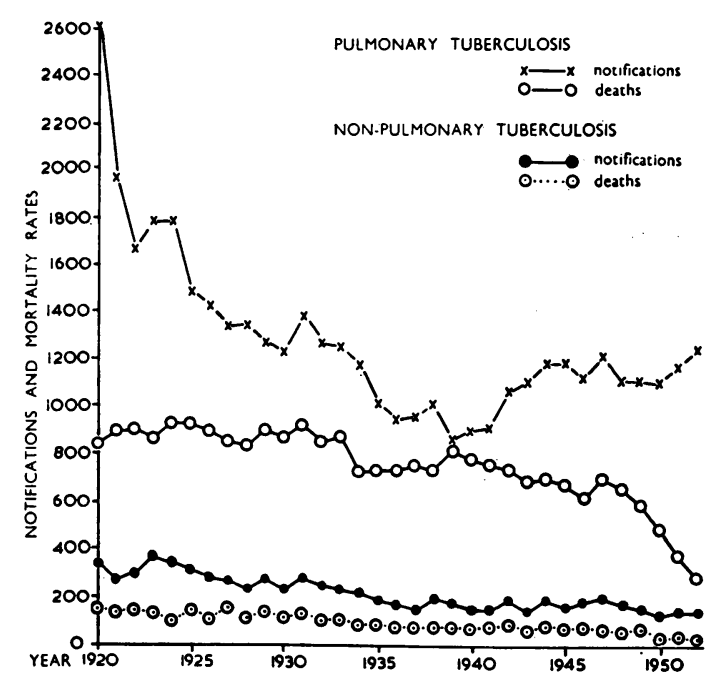
FIGURE.- Notifications of and deaths from tuberculosis in Birmingham,
$1920-52$

EXAMINATION OF REASONS FOR THE INCREASE IN Numbers OF Notifications

From data held in the records department of the Birmingham Chest Clinic it is possible to relate all new cases of respiratory tuberculosis examined to the source from which they came to the clinic. 
Before considering these data, however, we should enquire to what extent new cases examined in any one year at the Chest Clinic can be accepted as representative of all Birmingham notifications during that year (Table I). More than 90 per cent. of all notified cases were examined at least once at the clinic, and in 195274 per cent. were notified from the clinic (17 years ago the corresponding proportion was 36 per cent. It is certain, therefore, that any change in the pattern of identification or in the severity of cases of pulmonary tuberculosis notified in Birmingham will be reflected in the new cases examined at the chest clinic.

Between 1940 and 1952 the annual number of new cases seen at the Chest Clinic rose from 877 to 1,132 and we may now consider whether this increase has been associated with any substantial change in case-finding methods. Generally speaking a new patient arrives at an anti-tuberculosis centre by one of four main routes:

(a) A statutory notification has already been completed, either by a general practitioner or a hospital physician, and the patient has been asked to attend for confirmatory examination and supervision.

PERCENTAGE OF PERSONS NOTIFIED BECAUSE OF RESPIRATORY TUBERCULOSIS WHO WERE EXAMINED AT CHEST CLINIC

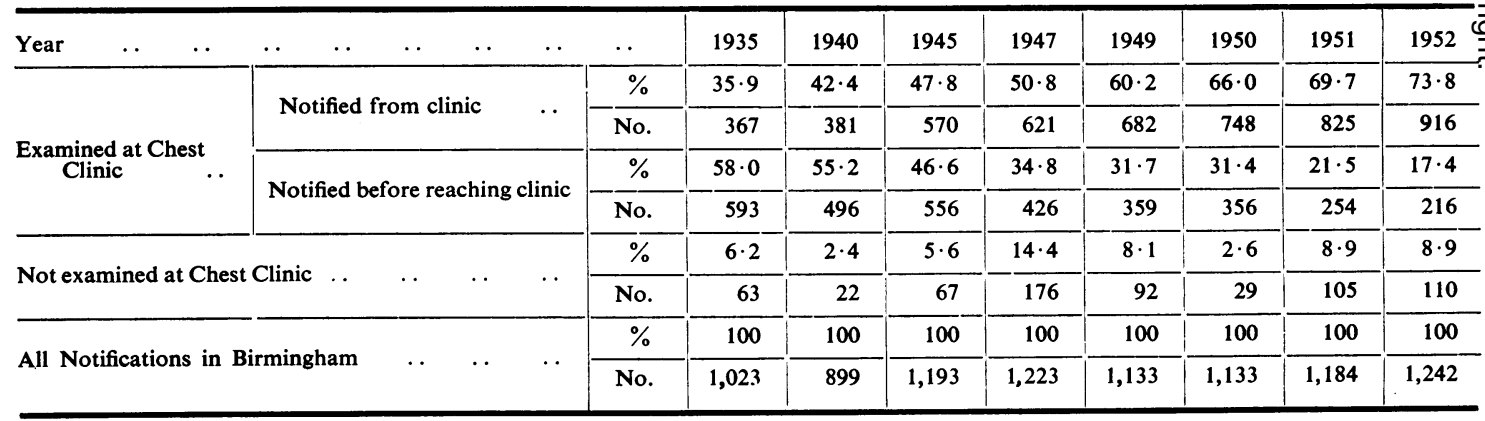

TABLE II

SOURCE OF NEW CASES OF RESPIRATORY TUBERCULOSIS SEEN AT CHEST CLINIC

\begin{tabular}{|c|c|c|c|c|c|c|c|c|c|c|c|c|}
\hline Year & .. & $\cdots$ & . & .. & 1935 & 1940 & 1945 & 1947 & 1949 & 1950 & 1951 & 1952 \\
\hline \multirow{2}{*}{ Notified . } & \multirow{2}{*}{$\cdots$} & \multirow[b]{2}{*}{$\cdots$} & \multirow{2}{*}{$\cdots$} & $\%$ & $61 \cdot 8$ & $56 \cdot 6$ & $49 \cdot 4$ & $40 \cdot 8$ & $34 \cdot 5$ & $32 \cdot 2$ & $23 \cdot 5$ & $19 \cdot 1$ \\
\hline & & & & No. & 593 & 496 & 556 & 426 & 359 & 356 & 254 & 216 \\
\hline \multirow{2}{*}{\multicolumn{2}{|c|}{ Referred as Suspects }} & \multirow{2}{*}{$\cdots$} & \multirow{2}{*}{$\cdots$} & $\%$ & $29 \cdot 8$ & $36 \cdot 9$ & $43 \cdot 5$ & $47 \cdot 4$ & $54 \cdot 6$ & $47 \cdot 6$ & $47 \cdot 5$ & $46 \cdot 6$ \\
\hline & & & & No. & 286 & 324 & 490 & 496 & 568 & 525 & 512 & 527 \\
\hline \multirow{2}{*}{\multicolumn{3}{|c|}{ Examined as Contacts .. }} & \multirow{2}{*}{$\cdots$} & $\%$ & $8 \cdot 4$ & $6 \cdot 5$ & $3 \cdot 6$ & $8 \cdot 4$ & $7 \cdot 5$ & $10 \cdot 6$ & $10 \cdot 8$ & $9 \cdot 6$ \\
\hline & & & & No. & 81 & 57 & 41 & 88 & 78 & 117 & 117 & 109 \\
\hline \multirow{2}{*}{\multicolumn{4}{|c|}{ Referred from Mass $X$ Ray Service }} & $\%$ & - & - & $3 \cdot 5$ & $3 \cdot 5$ & $3 \cdot 5$ & $9 \cdot 6$ & $18 \cdot 2$ & $24 \cdot 7$ \\
\hline & & & & No. & 0 & 0 & 39 & 37 & 36 & 106 & 196 & 280 \\
\hline \multirow{2}{*}{\multicolumn{2}{|c|}{ Total . . }} & \multirow[b]{2}{*}{$\cdots$} & \multirow{2}{*}{$\cdots$} & $\%$ & 100 & 100 & 100 & 100 & 100 & 100 & 100 & 100 \\
\hline & & & & No. & $\overrightarrow{960}$ & 877 & 1,126 & 1,047 & 1,041 & 1,104 & 1,079 & 1,132 \\
\hline
\end{tabular}


reason for the rise in notifications. The number of new cases derived from examination of contacts also increased (from 57 in 1940 to 109 in 1952), and the number of suspects found to have respiratory tuberculosis rose from 324 to 527 .

The increase in the number of suspects and contacts found to have pulmonary lesions may at first sight suggest that there has been a rise in incidence of respiratory tuberculosis among the general population from which they were drawn. Table III to some extent modifies this impression. Between 1940 and 1952 the annual number of suspects examined at the Clinic increased from 1,928 to 5,618 , and the number of contacts from 1,041 to 5,577 ; the percentages found to have pulmonary lesions fell from $16 \cdot 8$ to $9 \cdot 4$ and from $5 \cdot 5$ to $2 \cdot 0$ for the two groups respectively. That is to say that, while the number of examinations of individuals from these sources increased more than four times, the number of cases of pulmonary tuberculosis identified was not quite doubled. In passing, it is of some interest to note that although by 1952 the number of patients notified before examination at the Chest Clinic had fallen to less than half the number of 17 years ago, more than 30 per cent. of notifications were found to be incorrect.

The decline in the proportion of notifiable lesions among patients sent to the Chest Clinic as suspects does not by itself help us to arrive at any conclusion concerning changes in the incidence of tuberculosis in the general population, since it may be no more than an expression of an increased awareness of the value of early diagnosis and treatment by patients and their general practitioners. The fall in incidence among contacts examined at the Clinic, however, is more suggestive of a general fall in the incidence of clinically significant tuberculosis.

There is, of course, a possible alternative explanation. The remarkable increase between 1940 and 1952 in the annual number of contacts examined indicates that in the earlier years contact tracing was far from complete, and in these circumstances it is probable that the service was to some extent focused on families where the risk might be expected to have been greatest. But we can probably dismiss this possibility on the evidence presented in Table IV,

TABLE III

PERCENTAGE OF ALL NEW PATIENTS EXAMINED AT CHEST CliniC WHO WERE FOUND TO HAVE RESPIRATORY TUBERCULOSIS

\begin{tabular}{|c|c|c|c|c|c|c|c|c|c|c|c|c|}
\hline Year & . & .. & .. & .. & 1935 & 1940 & 1945 & 1947 & 1949 & 1950 & 1951 & 1952 \\
\hline \multirow{2}{*}{ Notified } & \multirow[b]{2}{*}{ 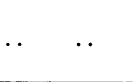 } & \multirow{2}{*}{. } & \multirow{2}{*}{.. } & $\%$ & $67 \cdot 3$ & $71 \cdot 9$ & $70 \cdot 3$ & 66.9 & $66 \cdot 1$ & $69 \cdot 9$ & $63 \cdot 8$ & $69 \cdot 5$ \\
\hline & & & & No. & 881 & 690 & 791 & 637 & 543 & 509 & 398 & 311 \\
\hline \multirow{2}{*}{\multicolumn{2}{|c|}{ Referred as Suspects }} & \multirow{2}{*}{. } & \multirow{2}{*}{. } & $\%$ & $18 \cdot 3$ & $16 \cdot 8$ & $11 \cdot 3$ & $9 \cdot 8$ & $8 \cdot 4$ & 8.7 & $8 \cdot 6$ & 9.4 \\
\hline & & & & No. & 1,559 & 1,928 & 4,354 & 5,064 & 6,796 & 6,027 & 5,964 & 5,618 \\
\hline \multirow{2}{*}{\multicolumn{3}{|c|}{ Examined as Contacts .. }} & \multirow{2}{*}{$\cdots$} & $\%$ & $7 \cdot 2$ & $5 \cdot 5$ & $4 \cdot 2$ & 3.9 & $3 \cdot 0$ & $3 \cdot 3$ & $3 \cdot 8$ & $2 \cdot 0$ \\
\hline & & & & No. & 1,131 & 1,041 & 966 & 2,255 & 2,585 & 3,523 & 3,085 & 5,577 \\
\hline \multirow{2}{*}{\multicolumn{3}{|c|}{$\begin{array}{l}\text { Referred from Mass } X \text { Ray } \\
\text { Service }\end{array}$}} & & $\%$ & - & - & $22 \cdot 9$ & $26 \cdot 2$ & $48 \cdot 6$ & $54 \cdot 9$ & $58 \cdot 5$ & $53 \cdot 1$ \\
\hline & & & & No. & - & - & 170 & 141 & 74 & 193 & 335 & 527 \\
\hline \multirow{2}{*}{\multicolumn{2}{|c|}{ Total . }} & \multirow{2}{*}{. } & \multirow{2}{*}{. } & $\%$ & $26 \cdot 9$ & $24 \cdot 0$ & $17 \cdot 9$ & $12 \cdot 9$ & $10 \cdot 5$ & $10 \cdot 8$ & $11 \cdot 0$ & $9 \cdot 4$ \\
\hline & & & & No. & 3,571 & 3,659 & 6,281 & 8,097 & 9,928 & 10,252 & 9,782 & 12,035 \\
\hline
\end{tabular}

TABLE IV

PERCENTAGE GROUP I AMONG NEW CASES OF RESPIRATORY TUBERCULOSIS EXAMINED AT CHEST CLINIC RELATED TO SOURCE

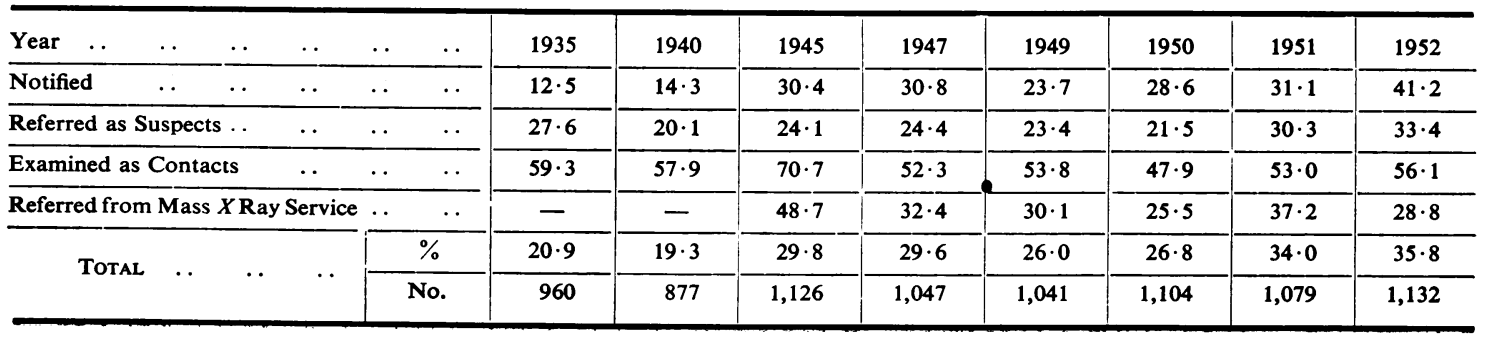


TABLE V

CLASSIFICATION OF NEW CASES OF RESPIRATORY TUBERCULOSIS SEEN AT CHEST CLINIC

\begin{tabular}{|c|c|c|c|c|c|c|c|c|c|c|c|c|}
\hline Year .. & $\cdots$ & . & . & 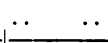 & 1935 & 1940 & 1945 & 1947 & 1949 & 1950 & 1951 & 1952 \\
\hline \multirow{2}{*}{ Group I . . } & \multirow[b]{2}{*}{. } & \multirow{2}{*}{$\cdots$} & \multirow{2}{*}{. } & $\%$ & $20 \cdot 9$ & $19 \cdot 3$ & $29 \cdot 8$ & $29 \cdot 6$ & $26 \cdot 0$ & $26 \cdot 8$ & $34 \cdot 0$ & $35 \cdot 8$ \\
\hline & & & & No. & 201 & 169 & 335 & 310 & 271 & 296 & 367 & 406 \\
\hline \multirow{2}{*}{ Group II. . } & \multirow[b]{2}{*}{. } & \multirow{2}{*}{$\cdots$} & \multirow{2}{*}{. } & $\%$ & $43 \cdot 0$ & $38 \cdot 5$ & $41 \cdot 0$ & $44 \cdot 4$ & $51 \cdot 5$ & $50 \cdot 4$ & $46 \cdot 6$ & $48 \cdot 1$ \\
\hline & & & & No. & 413 & 338 & 462 & 465 & 536 & 556 & 503 & 544 \\
\hline \multirow{2}{*}{ Group III } & \multirow{2}{*}{$\cdots$} & \multirow{2}{*}{$\cdots$} & \multirow{2}{*}{$\cdots$} & $\%$ & $36 \cdot 0$ & $42 \cdot 2$ & $29 \cdot 2$ & $26 \cdot 0$ & $22 \cdot 5$ & $22 \cdot 8$ & $19 \cdot 4$ & $16 \cdot 1$ \\
\hline & & & & No. & 346 & 370 & 329 & 272 & 234 & 252 & 209 & 182 \\
\hline \multirow{2}{*}{ Total } & \multirow{2}{*}{. } & \multirow{2}{*}{. } & \multirow{2}{*}{$\cdots$} & $\%$ & 100 & 100 & 100 & 100 & 100 & 100 & 100 & 100 \\
\hline & & & & No. & 960 & 877 & 1,126 & 1,047 & 1,041 & 1,104 & 1,079 & 1,132 \\
\hline
\end{tabular}

which shows the proportion of early cases (Group I) among new cases of respiratory tuberculosis identified at the clinic. Between 1940 and 1952, among all new cases, the percentage in Group I increased from $19 \cdot 3$ to $35 \cdot 8$; but among contacts there was no appreciable change.

\section{Discussion}

The data examined above provide support for the view that the recent rise in notification rates is due to more successful case finding, rather than to a raised incidence of the disease. The increase in the number of new cases discovered between 1940 and 1952 was due to mass radiography, which came into use during these years, and to an increase (by about four times) in the number of persons examined at the Chest Clinic as suspects and contacts. In the same period the proportion of suspects and contacts found to have clinically significant tuberculosis fell very considerably. While the evidence in the case of suspects is hard to interpret, the reduced incidence among contacts strongly suggests that the incidence of the disease must also have fallen and certainly indicates that it has not risen. It is hardly correct to attribute the more successful case finding wholly to mass radiography (as was done in the Annual Report of the Ministry of Health, 1951), since about half the increase between 1940 and 1952 was due to the extension of the work among suspects and contacts.

Finally, it may be noted that the increase in the number of cases discovered is associated with an increase in the proportion of early cases (Table V). During the 13 years considered the number of early (Group I) cases examined at the clinic increased nearly three times (from 169 to 406), while the number of late (Group III) cases fell by half (from 346 to 192 ). Since early respiratory tuberculosis is more amenable to treatment, it seems certain that more intensive methods of case finding have made a considerable contribution to the recent decline in mortality rates, which cannot be attributed wholly to advances in therapy.

\section{SUMmaRY}

(1) During recent years in Birmingham, as in England and Wales, the number of notifications of respiratory tuberculosis has increased while the number of deaths has fallen. Data collected from the Birmingham Chest Clinic (where more than 90 per cent. of all Birmingham notifications are examined) are used to inquire whether the high rate of notification is due to a raised incidence of the disease or to improved case finding.

(2) It is shown that between 1940 and 1952 the number of new cases notified before examination at the Clinic fell from 496 to 216 . The increase in the number of notifications from all sources (from 877 to 1,132 ) is due about equally to:

(a) cases discovered by mass radiography ( 280 in 1952),

(b) an increase in cases identified among suspects and contacts (from 381 to 636).

(3) In the same period, the proportion of patients with notifiable lesions discovered among suspects and contacts examined at the Clinic fell from 17 per cent. to 9 per cent. and from 6 per cent. to 2 per cent. respectively. The fact that the number of new cases from these two sources was almost doubled is explained by the fact that four times as many persons were examined.

(4) These observations strongly support the accepted view that the raised incidence of notification is due to more effective case finding.

We acknowledge with pleasure the facilities afforded to us by Dr. Matthew Burn, Medical Officer of the City of Birmingham, and the assistance of Mr. L. Barratt in finding our way through the Birmingham Chest Clinic records.

\section{REFERENCES}

Ministry of Health (1953). "Report for the Year 1951", Part III. H.M.S.O., London.

Stocks, P. (1952). In "Modern Practice in Tuberculosis", ed. T. H Sellers and J. L. Livingstone, vol. 1, pp. 8-27. Butterworth, London. 